Lee, S. L. (2021). Social network sites and obsessive-compulsive disorder: An investigation with suppression analyses. Cyberpsychology: Journal of Psychosocial Research on Cyberspace, 15(2), Article 5.

https://doi.org/10.5817/CP2021-2-5

\title{
Social Network Sites and Obsessive-Compulsive Disorder: An Investigation With Suppression Analyses
}

\author{
Soon L. Lee \\ Monash University Malaysia, Subang Jaya, Malaysia
}

\begin{abstract}
This research examined the relationship between social network site (SNS) intensity, SNS addiction, and the severity of obsessive-compulsive disorder (OCD), alongside its factors of obsession and compulsion. The overlap of SNS intensity and SNS addiction was controlled in the study to predict the measured severity of OCD. In this study, 204 Malaysian undergraduate students were recruited to complete the revised Facebook Intensity Scale, the revised Bergen Facebook Addiction Scale, and the self-report version of the Yale-Brown Obsessive-Compulsive Scale. The overlap of SNS intensity and SNS addiction was supported by their significant positive correlation. Furthermore, SNS addiction significantly correlated with the measured OCD and its corresponding factors. The hierarchical regression analysis revealed that the entry of SNS intensity enhanced the facilitative effect of SNS addiction on OCD and its factors. Therefore, the role of SNS intensity as a suppressor was supported. In the same regression model, SNS intensity predicted the severity of OCD and its compulsion subscale negatively. Implications and directions for future research were also discussed in this manuscript.
\end{abstract}

Keywords: Obsessive-compulsive disorder; social network sites addiction; social network sites intensity suppression analyses; suppression effects

\section{Introduction}

Social network sites (SNS) have formed a significant part of people's lives in the contemporary world to the extent that SNS users are heavily dependent on these platforms (Kuss \& Griffiths, 2017). The ubiquitous SNS have been a central research area, and empirical investigations have widely examined the possible antecedents that stimulate their popularity (e.g., Scott, 2014), as well as the potentially harmful effects from prolonged exposure to these online platforms (e.g., Andreassen et al., 2016). When the notion of Facebook depression was first introduced (O'Keeffe et al., 2011), researchers invested various empirical efforts to determine the validity of this concern (e.g., Pantic et al., 2012). However, mixed findings have been suggested; certain efforts supported the possibility of developing depression through prolonged exposure to SNS (e.g., Pantic et al., 2012), while another stream of research concluded that this concern is premature (e.g., Jelenchick et al., 2013). Subsequent studies further revealed that the prolonged use of SNS is associated with other clinical symptoms, and research outcomes have supported the likelihood to develop symptoms of obsessive-compulsive disorder (OCD; Andreassen et al., 2016; Lee et al., 2015). The correlational design employed in a study by Lee et al. (2015), suggested that Facebook overuse stimulates cognitive patterns that are exclusive to OCD, eventually inducing higher levels of OCD severity. The subsequent analysis also showed that bidirectionality was not evident, further supporting the facilitative role of Facebook overuse. In the recent Diagnostic and Statistical Manual of Mental Disorders (American Psychiatric Association, 2013), the diagnosis of OCD requires the presence of both or one of the corresponding symptoms of obsessions (recurrent and persistent stress-inducing thoughts) or compulsions (ritual-like behaviours performed 
rigidly to alleviate the distress from obsessions). Although the link between SNS and OCD has been supported empirically, it remains underappreciated; hence, necessitating more comprehensive efforts to expand this research topic (see Hussain \& Griffiths, 2018). Given this circumstance, the present research intends to examine the conceptual link between SNS use and OCD.

This study utilised standardised measures to measure the use of SNS in order to avoid any complications. Although the duration of SNS use can be conceptually relevant to OCD, this research did not incorporate this element as an indicator of SNS use for the following reasons: (1) the estimated time spent on online platforms such as Facebook may not be conceptually meaningful, i.e. it fails to convey any meaningful interpretations (McCord et al., 2014; Rosen et al., 2013; Selfhout et al., 2009; Sheldon, 2008); (2) this form of estimation lacks validity since users tend to overestimate their time spent using SNS (Junco, 2013); (3) the invariant unit of estimation (e.g., time spent in minutes or hours per day) hinder interpretations and comparability of the results (Anderson et al., 2012; Rosen et al., 2013). Considering these limitations, this research utilised two standardised measures that evaluated different aspects of SNS usage.

\section{SNS Intensity}

The Facebook Intensity Scale (FIS) is a brief measure that was devised as an alternative to frequency and duration estimations of Facebook use (Ellison et al., 2007). As the pioneer of SNS measures, the FIS can be considered a common indicator of SNS engagement (Sigerson \& Cheng, 2018). In previous empirical attempts, the wordings of these items were changed to fit the broad context of SNS (e.g., Lee et al., 2016). The term 'intensity' refers to active usage, emotional connection to the platform, and the degree of integration of the platform into daily life (see Ellison et al., 2007). This scale was employed in research that examined the relationship of SNS intensity and social capital, and results have supported the facilitative effect of SNS intensity on social capital amongst those with low self-esteem (Steinfield et al., 2008) and low self-satisfaction (Ellison et al., 2007; Steinfield et al., 2008). Findings also suggested that high SNS engagement increases life satisfaction and social trust (e.g., Valenzuela et al., 2009). Overall, it can be observed that past research has acknowledged that SNS intensity may have a positive influence on users' psychological (e.g., Valenzuela et al., 2009) and social well-being (e.g., Ellison et al., 2007). Therefore, high levels of SNS engagement do not lead to clinical conditions such as depression, anxiety, and stress (Labrague, 2014). Based on previous findings that supported the benefits of SNS intensity on different aspects of users' wellbeing including social capital (e.g., Ellison et al., 2007), the current research postulates SNS intensity as a form of adaptive SNS use.

\section{SNS Intensity and OCD}

The intensity of SNS usage, which reflects on the overall SNS engagement (Sigerson \& Cheng, 2018), can be conceptually relevant to OCD. Previous studies have posited that active SNS usage may escalate into SNS addiction (Błachnio, Przepiorka, \& Hawi, 2016; Brailovskaia et al., 2018; Orosz et al., 2016; Xie \& Karan, 2019), as the manifested behavioural addiction has been linked to OCD (Lee et al., 2015). It is theoretically plausible that the active use of SNS is a manifestation of OCD. Nonetheless, based on the reviewed findings, it is counterintuitive to expect a link between SNS intensity and the severity of OCD. In particular, this form of usage can be conceptually adaptive to users, as exemplified by previous literature that supported its facilitative effect on users' social wellbeing (e.g., Ellison et al., 2007).

Accordingly, it must be emphasised that high levels of SNS engagement do not necessarily translate into maladaptive aspects (Labrague, 2014); hence, this contradicts with the claim which described SNS engagement as a prerequisite to SNS addiction (Błachnio, Przepiorka, \& Hawi, 2016; Brailovskaia et al., 2018; Orosz et al., 2016; Xie \& Karan, 2019). To resolve this uncertainty, the current research will further explore the association between SNS intensity and OCD. Postulating SNS intensity as a form of adaptive SNS use, this study anticipates a non-significant relationship between SNS intensity and the measured severity of OCD.

\section{SNS Addiction}

The notion of addiction towards SNS was first investigated by Wilson et al. (2010) who characterised the phenomenon according to three components of saliency, loss of control, and withdrawal. Subsequent research 
conducted by Andreassen et al. (2012) proposed six components of Facebook addiction, namely saliency, mood modification, tolerance, withdrawal, conflict, and relapse. These researchers also developed a brief measure known as the Bergen Facebook Addiction Scale (BFAS) to gauge this specific form of behavioural addiction, in which the scale has stimulated substantial progress in this area of research. The BFAS has also been recommended as a reliable measure of SNS since it has been properly validated (Sigerson \& Cheng, 2018). Empirical findings revealed the maladaptive aspects of SNS addiction such that it corresponds to poor psychological functioning, including low life satisfaction (e.g., Biolcati et al., 2018; Satici, 2019; Satici \& Uysal, 2015) and low self-esteem (e.g., Uysal et al., 2013). Further research also implied that this form of behavioural addiction intensifies the severity of clinical disorders, such as depression (e.g., da Veiga et al., 2019; Foroughi et al., 2019). It is also worth highlighting that the terms SNS addiction and problematic SNS use are used interchangeably in the literature (e.g., Satici \& Uysal, 2015). Therefore, this research postulates that SNS addiction represents a form of maladaptive use of SNS.

\section{SNS Addiction and OCD}

It must be emphasised that the link between SNS addiction and OCD has been supported by previous empirical studies (Andreassen et al., 2016; Lee et al., 2015). This relationship is plausible such that users may have a constant urge to check their profiles for updates (Andreassen et al., 2016) which is possibly resulted from unrealistic catastrophic thoughts (Lee et al., 2015). These findings are also theoretically consistent with the existing findings on OCD. Kashyap et al. (2012) claimed that the severity of OCD is dependent on individuals' capacity to regulate and monitor the apparent symptoms. One's failure to regulate the use of SNS is an indication of poor selfregulation and high levels of impulsivity (e.g., Fowler et al., 2020), which further intensifies the severity of OCD (Kashyap et al., 2012). Therefore, it can be argued that SNS addiction is more conceptually related to OCD compared to SNS intensity. Considering this relationship, the present research anticipates a significant positive relationship between SNS addiction and the severity of OCD.

\section{SNS Intensity and SNS Addiction}

Although SNS intensity and SNS addiction differ in terms of definitions, empirical evidence has identified the overlap of these phenomena. According to Kuss and Griffiths (2017), there is a subtle distinction between habitual regular use and problematic addictive use of SNS. This is demonstrated by the robust positive correlation of SNS intensity and SNS addiction (Błachnio et al., 2015; Błachnio et al., 2017; Błachnio \& Przepiorka, 2016; Błachnio, Przepiorka, \& Pantic, 2016; Brailovskaia et al., 2018; Brailovskaia et al., 2019; Orosz et al., 2016; Przepiorka \& Błachnio, 2016; Turley et al., 2019). This correlation further suggests that high levels of SNS intensity increase the risk of SNS addiction (Błachnio, Przepiorka, \& Pantic, 2016; Przepiorka \& Błachnio, 2016). Therefore, it is conceptually deduced that SNS intensity is a prerequisite to SNS addiction, but not vice-versa (Błachnio, Przepiorka, \& Hawi, 2016; Brailovskaia et al., 2018; Orosz et al., 2016; Xie \& Karan, 2019).

As suggested by the reviewed findings, these aspects relate differently to the same outcome. With regard to life satisfaction, it has been shown that SNS intensity increases life satisfaction (e.g., Valenzuela et al., 2009), while SNS addiction decreases the same aspect of satisfaction (e.g., Satici \& Uysal, 2015). Hence, these findings suggest that SNS intensity and SNS addiction are two distinct concepts despite the overlap that has been suggested previously (e.g., Błachnio \& Przepiorka, 2016). Nevertheless, it should be emphasised that this overlap requires a more comprehensive investigation since it can cause the empirical research outcome to be muddled. For instance, SNS intensity was identified as a factor that simultaneously facilitates (e.g., Valenzuela et al., 2009) and deteriorates (e.g., Błachnio, Przepiorka, \& Hawi, 2016) the degree of life satisfaction.

The lack of consistency in such findings implies that the construct of SNS intensity is overlapping with another theoretical construct. As discussed previously, a unidimensional measure can contain multiple components that obscure the theoretical construct of interest (Watson et al., 2013). Given this situation, it is highly plausible that SNS intensity is overlapping with SNS addiction (Błachnio, Przepiorka, \& Pantic, 2016; Przepiorka \& Błachnio, 2016), and the shared variance of these two individual aspects may have obscured the actual discrepancy (e.g., Watson et al., 2013), further confounding the research findings and their subsequent interpretations. The overlap of these constructs can be explained through the notion of "jingle-jangle fallacies" (Marsh, 1994). Jingle fallacy refers to an inaccurate assumption that two separate measures represent an identical concept (Thorndike, 1904), whereas 
jangle fallacy is the assumption that two different measures signify two separate constructs when in fact they capture the same or closely related construct (Kelley, 1927). Accordingly, the assumption that SNS intensity is embedded in SNS addiction (Błachnio, Przepiorka, \& Hawi, 2016; Brailovskaia et al., 2018; Orosz et al., 2016; Xie \& Karan, 2019) suggests a tendency to succumb to jingle fallacy (Thorndike, 1904). Therefore, this research has conducted suppressor analyses to differentiate these two overlapping dimensions.

\section{Suppression Effects}

While a consensus is yet to be reached concerning defining suppression, it should be noted that its conceptualisation varies across the literature (Gaylord-Harden et al., 2010). Suppressor variable is a variable that enhances the predictive power of a predictive model in multiple regression (Horst, 1941). Although it does not relate meaningfully to the outcome, it forms a meaningful relationship with another predictor (see Horst, 1941). Horst (1941) also explained that the entry of the suppressor, i.e. the variable that has no meaningful relationship with the outcome variable, controls for irrelevant variance in the other predictor, consequently enhancing its predictive power. Apart from Horst's (1941) classical suppressor, other types of suppressor effects include reciprocal (Conger, 1974) or cooperative suppression (J. Cohen \& P. Cohen, 1975), and net (J. Cohen \& P. Cohen, 1975) or cross-over suppression (Paulhus et al., 2004). Reciprocal or cooperative suppression occurs when the two predictors correlate positively with each other but correlate negatively with the outcome, or both predictors are inversely correlated but correlate positively with the outcome (J. Cohen \& P. Cohen, 1975; Conger, 1974). In any of these cases, the inclusion of the identified suppressor increases the beta weights of the predictors. Net or crossover suppression occurs when the predictors and the outcome are positively correlated, and the inclusion of both predictors increases the beta weight of the stronger predictor and changes the sign of the weaker predictor (J. Cohen \& P. Cohen, 1975). Despite the criticisms including frequent failures to replicate suppression effects (e.g., Paulhus et al., 2004; Wiggins, 1973) and the limited practical value of these findings (Wiggins, 1973), suppressor analyses are valuable in consolidating theories (Cheung \& Lau, 2008) and in clarifying theoretical constructs of overlapping variables (Paulhus et al., 2004; Watson et al., 2013). Accordingly, the present research can be a valuable addition to the literature such that the vague and ill-defined constructs of SNS will be clarified (e.g., Frost \& Rickwood, 2017).

\section{The Present Research}

This research intends to examine the relationships between SNS intensity, SNS addiction, and the measured severity of OCD by exploring the adaptive aspects of SNS intensity and the pathology of SNS addiction. Since the overlap of these two constructs is contrasting the present argument, suppressor analyses will be conducted to disentangle this overlap. Based on previous findings, SNS addiction is expected to demonstrate significant positive relationships with SNS intensity (e.g., Błachnio, Przepiorka, \& Pantic, 2016) and the severity of OCD (Andreassen et al., 2016; Lee et al., 2015). Furthermore, it must be noted that following Horst's (1941) criteria, SNS addiction is not a suppressor variable. On the other hand, SNS intensity does fulfil the criteria of suppressor variable proposed by Horst (1941) as it is expected to correlate with SNS addiction (e.g., Błachnio, Przepiorka, \& Pantic, 2016), but not with the measured severity of OCD. Its link with the severity of OCD can be dismissed since previous findings have demonstrated that SNS intensity did not form any meaningful relationships with pathological aspects such as depression, anxiety, and stress (Labrague, 2014). Therefore, this research posits that the entry of SNS intensity will affect the explanatory power of SNS addiction in predicting the severity of OCD, exemplifying the case of classical suppression described by Horst (1941).

\section{Method}

\section{Participants}

In this research, 204 Malaysian undergraduate students were successfully recruited to be the research participants. The majority of these individuals identified themselves as female $(n=124,61 \%)$, followed by male ( $n$ $=77,38 \%)$, and those who refused to disclose their gender $(n=3,1 \%)$. The final sample consisted mainly of Chinese ( $n=99,49 \%)$, followed by Malays ( $n=79,39 \%)$, those from other ethnic groups $(n=18,9 \%)$, and Indians $(n=8$, $4 \%)$. The mean age was $22.93(S D=3.43)$. Table 1 summarises these details. 


\begin{tabular}{lc}
\hline Demographic & $n(\%)$ \\
\hline Gender & $77(38 \%)$ \\
Male & $124(61 \%)$ \\
Female & $3(1 \%)$ \\
Refused to disclose & \\
Ethnicity & $79(39 \%)$ \\
Malay & $99(49 \%)$ \\
Chinese & $8(4 \%)$ \\
Indian & $18(9 \%)$ \\
Others & $M(S D)$ \\
Age & $22.93(3.43)$ \\
\hline
\end{tabular}

\section{Procedure}

This research was initially advertised in the lecture halls and classrooms of an international university branch in Malaysia. Participants were informed that this research was open to (1) SNS users (2) who are Malaysians (3) at the legal age of 18 and above. Data were collected between the duration of March 2017 - March 2018. Any potential participants were invited to contact the researcher in order to complete the questionnaire for this research. Recruiting non-clinical sample such as undergraduate students does not contradict the aim of this research which particularly targets young adults who are active users of SNS (e.g., Kim \& Shen, 2020) since obsessiveness and compulsiveness are also common in non-clinical populations (Gibbs, 1996; Rachman \& de Silva, 1978; Steketee et al., 1996).

The participants were also informed of the purpose of this research, their basic rights to confidentiality and anonymity, and relevant procedures involved if they decided to withdraw from this study. Implied consent marked by the submission of responses was sought instead of informed consent. Since no identifier was assigned to the printed questionnaires to ensure anonymity, participants were allowed to withdraw before submitting the questionnaires. It should be mentioned that monetary reward was neither offered nor given to any of the research participants to ensure voluntary participation. Lastly, ethical approval for the research was granted by MUHEC.

Outliers were identified with the following criteria: (1) z score larger than 3.29, (2) a $p<.001$ for Mahalanobis' distance, and (3) a Cook's distance larger than 1.00 (Tabachnick \& Fidell, 2012). Two univariate outliers were found for Obsessive and Compulsive subscales, respectively. These values were then transformed to a smaller value to reduce their impact. No multivariate outlier was found, as suggested by the Mahalanobis' distance and Cook's distance. Normality was assumed if the variables exhibited skewness $< \pm 2$ and kurtosis $< \pm 3$ (Kline, 2005). The range of skewness (-.24 to .46) and kurtosis (-.49 to .04) indicated that these variables were normally distributed.

\section{Measures}

SNS intensity was measured with the adapted FIS (Ellison et al., 2007), and this scale comprised of eight items representing attitudinal and emotional aspects of SNS use. Six of these items were rated using a 5-point scale (1 $=$ Strongly disagree, $5=$ Strongly agree $)$. Similarly, the items that reflect on the number of friends $(1=0-50,5=$ More than 400) and the amount of time spent on SNS ( $1=10-30$ minutes, $5=$ More than 3 hours $)$ were rated using a 5point scale. All of these items were also reworded to match the broad context of SNS (e.g., SNS are part of my everyday activity; see Lee et al., 2016). The Cronbach's a of this scale was .79.

SNS addiction was measured with the adapted BFAS (Andreassen et al., 2012), and this scale comprised six items that reflected on the addictive use of SNS. These items were also rated using a 5-point scale $(1=$ Very rarely, $5=$ Very often), and they were reworded to match the broad context of SNS (e.g., How often during the last year did you use SNS to forget about personal problems?). The Cronbach's a of this scale was .85 . 
The severity of OCD was measured using the Yale-Brown Obsessive-Compulsive Scale (Goodman, Price, Rasmussen, Mazure, Delgado, et al., 1989; Goodman, Price, Rasmussen, Mazure, Fleischmann, et al., 1989), and this research utilised the self-report version (Steketee et al., 1996). This scale comprised ten items ( $\alpha=.88)$, with five of these items forming the obsession component (e.g., How much have your obsessive thoughts caused you distress?; $\alpha=.82$ ) and the remaining five items forming the compulsion component (e.g., How much of an effort did you make to resist the compulsions?; $a=.78$ ). These items were rated based on a 5 -point scale (e.g., $0=$ None, 4 = Incapacitating). Although these measures were used primarily with clinical patients (e.g., Goodman, Price, Rasmussen, Mazure, Delgado, et al., 1989), empirical evidence revealed that they could be used with non-clinical samples (Steketee et al., 1996), including undergraduate students (e.g., Seol et al., 2013).

\section{Results}

\section{Descriptive Statistics and Correlations}

Means, standard deviations, and the correlation coefficients for Pearson's correlation are summarised in Table 2. Correlation coefficients that ranged from .10 to .30 were interpreted as small, .30 to .50 were interpreted as moderate, and those larger than .50 were interpreted as large (J. Cohen, 1988). The analysis revealed that SNS intensity was positively correlated with SNS addiction such that the correlation coefficients indicated a strong relationship between SNS intensity and SNS addiction. The measured severity of OCD and its corresponding subscales were all significantly correlated with SNS addiction. The correlation coefficients further suggested that the measured severity of OCD and its Obsessive and Compulsive subscales were weakly associated with SNS addiction. However, the measured severity of OCD and its factors of obsession and compulsion did not correlate significantly with SNS intensity. Despite the strong relationship between SNS intensity and SNS addiction, the correlation coefficient was less than .70, suggesting the absence of multicollinearity (Tabachnick \& Fidell, 2012). Moreover, the Variance Inflation Factor (VIF) that ranged between 1.46 and 2.37 did not exceed the imposed threshold of 10, indicating the absence of multicollinearity (Farrar \& Glauber, 1967).

Table 2. Descriptive Statistics and Correlations.

\begin{tabular}{lcccccc}
\hline Variables & $M(S D)$ & 1 & 2 & 3 & 4 & 5 \\
\hline 1. SNS addiction & $15.19(5.28)$ & 1 & $.53^{* *}$ & $.33^{* *}$ & $.35^{* *}$ & $.27^{* *}$ \\
2. SNS intensity & $26.07(6.04)$ & - & 1 & .05 & .08 & .02 \\
3. OCD & $10.62(6.48)$ & - & - & 1 & $.93^{* *}$ & $.93^{* *}$ \\
4. Obsessive & $5.87(3.48)$ & - & - & - & 1 & $.73^{* *}$ \\
5. Compulsive & $4.74(3.48)$ & - & - & - & - & 1 \\
\hline Note. ${ }^{*} p<.05,{ }^{* *} p<.01$. & & & & &
\end{tabular}

\section{Hierarchical Regression}

Two predictive models were tested to address the research aim. In the first model, SNS addiction was entered in the first step and subsequently followed by SNS intensity. This was conducted to determine whether or not SNS intensity is a suppressor variable. In the second model, the order of entry of these predictors was reversed, whereby the measured SNS intensity was entered in the first step, followed by SNS addiction. The significance of these suppressor effects was then evaluated using the Sobel test (see MacKinnon et al., 2000; Paulhus et al., 2004). The results of the hierarchical regression are summarised in Table 3. In general, when the measured SNS addiction and SNS intensity were entered into the same predictive model, results indicated that SNS addiction predicted greater severity of OCD and its corresponding symptoms, whereas SNS intensity predicted these aspects negatively.

In the first model, SNS addiction that was entered in the first step significantly predicted the measured severity of $\operatorname{OCD}(\beta=.33, p<.001)$, the degree of obsession $(\beta=.35, p<.001)$, and compulsiveness $(\beta=.27, p<.001)$. In the subsequent step, the entry of the measured SNS intensity enhanced the coefficients of SNS addiction in predicting the severity of $\operatorname{OCD}(\beta=.42, p<.001)$, the degree of obsession $(\beta=.42, p<.001)$ and compulsiveness $(\beta=.36, p<$ $.001)$. In the same step, SNS intensity significantly predicted the severity of OCD $(\beta=-.17, p<.001)$ and compulsiveness $(\beta=-.18, p<.001)$. The negative coefficients suggested that SNS intensity reduced the severity of 
OCD and the degree of compulsiveness. Notwithstanding its negative effect, SNS intensity did not significantly predict the obsessive aspect of OCD $(\beta=-.14, p>.05)$. The Sobel test supported the significance of the suppressor effects, except for the effects of SNS addiction and SNS intensity on the obsessive subscale.

Table 3. Summary of Hierarchical Regression.

\begin{tabular}{|c|c|c|c|c|c|c|c|c|c|}
\hline \multirow{2}{*}{ Predictor/s } & \multicolumn{3}{|c|}{ OCD } & \multicolumn{3}{|c|}{ Obsessive } & \multicolumn{3}{|c|}{ Compulsive } \\
\hline & $b$ & $\beta$ & $t$ & $b$ & $\beta$ & $t$ & $b$ & $\beta$ & $t$ \\
\hline \multicolumn{10}{|l|}{ Model 1} \\
\hline \multicolumn{10}{|l|}{ Step 1} \\
\hline \multirow[t]{2}{*}{ SNS addiction } & $0.41^{\star \star \star}$ & $.33^{* \star *}$ & $5.01^{* \star \star}$ & $0.23^{* \star *}$ & $.35^{* \star *}$ & $5.34^{\star \star \star}$ & $0.18^{\star \star \star}$ & $.27^{\star \star \star}$ & $3.97^{* * *}$ \\
\hline & \multicolumn{3}{|c|}{$R^{2}=.11, F(1,202)=25.10^{\star * *}$} & \multicolumn{3}{|c|}{$R^{2}=.12, F(1,202)=28.03^{* * *}$} & \multicolumn{3}{|c|}{$R^{2}=.07, F(1,202)=15.83^{* * *}$} \\
\hline \multicolumn{10}{|l|}{ Step 2} \\
\hline SNS addiction & $0.52^{* \star \star}$ & $.42^{* \star \star}$ & $5.45^{* * *}$ & $0.28^{* * *}$ & $.42^{* \star \star}$ & $5.47^{\star \star \star}$ & $0.24^{\star \star \star}$ & $.36^{* \star *}$ & $4.61^{* * *}$ \\
\hline \multirow[t]{2}{*}{ SNS intensity } & $-0.18^{*}$ & $-.17^{*}$ & $-2.21^{*}$ & -0.08 & -.14 & -1.80 & $-0.10^{*}$ & $-.18^{*}$ & $-2.27^{*}$ \\
\hline & \multicolumn{3}{|c|}{$\begin{array}{c}R^{2}=.13, \Delta R^{2}=.02, F(2,201)= \\
15.23^{\star * *}, \text { Sobel test }=-2.06^{*}\end{array}$} & \multicolumn{3}{|c|}{$\begin{array}{c}R^{2}=.13, \Delta R^{2}=.01, F(2,201)= \\
15.80^{* * *}, \text { Sobel test }=-1.71\end{array}$} & \multicolumn{3}{|c|}{$\begin{array}{c}R^{2}=.09, \Delta R^{2}=.02, F(2,201)= \\
10.65^{* *}, \text { Sobel test }=-2.03^{*}\end{array}$} \\
\hline \multicolumn{10}{|l|}{ Model 2} \\
\hline \multicolumn{10}{|l|}{ Step 1} \\
\hline \multirow[t]{2}{*}{ SNS intensity } & 0.06 & .05 & 0.77 & 0.05 & .09 & 1.23 & 0.01 & .02 & 0.21 \\
\hline & \multicolumn{3}{|c|}{$R^{2}=.003, F(1,202)=0.59$} & \multicolumn{3}{|c|}{$R^{2}=.01, F(1,202)=1.50$} & \multicolumn{3}{|c|}{$R^{2}=.00, F(1,202)=0.04$} \\
\hline \multicolumn{10}{|l|}{ Step 2} \\
\hline SNS intensity & $-0.18^{*}$ & $-.17^{*}$ & $-2.21^{*}$ & -0.08 & -.14 & -1.80 & $-0.10^{*}$ & $-.18^{*}$ & $-2.27^{*}$ \\
\hline \multirow[t]{2}{*}{ SNS addiction } & $0.52^{\star \star \star}$ & $.42^{* \star \star}$ & $5.45^{\star \star \star}$ & $0.28^{* \star *}$ & $.42^{* \star \star}$ & $5.47^{\star \star \star}$ & $0.24^{\star \star \star}$ & $.36^{* \star *}$ & $4.61^{* * *}$ \\
\hline & \multicolumn{3}{|c|}{$\begin{array}{c}R^{2}=.13, \Delta R^{2}=.13, F(2,201)= \\
15.23^{* \star *}, \text { Sobel test }=-2.06^{*}\end{array}$} & \multicolumn{3}{|c|}{$\begin{array}{c}R^{2}=.14, \Delta R^{2}=.13, F(2,201)= \\
15.80^{\star \star *}, \text { Sobel test }=-1.71\end{array}$} & \multicolumn{3}{|c|}{$\begin{array}{c}R^{2}=.09, \Delta R^{2}=.09, F(2,201)= \\
10.65^{* * *}, \text { Sobel test }=-2.03^{*}\end{array}$} \\
\hline
\end{tabular}

Note. ${ }^{*} p<.05,{ }^{* *} p<.01,{ }^{* * *} p<.001$.

In the second model, SNS intensity that was entered in the first step did not significantly predict the measured severity of OCD $(\beta=.05, p>.05)$, obsession $(\beta=.09, p>.05)$, and compulsiveness $(\beta=.02, p>.05)$. With the entry of SNS addiction, the intensity of SNS use emerged as significant predictors of the measured severity of OCD $(\beta=$ $-.17, p<.05)$ and compulsiveness $(\beta=-.18, p<.05)$. The negative coefficients suggested that SNS intensity reduces the severity of OCD and compulsiveness. However, it did not significantly predict the obsession aspect of OCD ( $\beta$ $=-.14, p>.05)$. In this model, SNS addiction significantly predicted the severity of $\operatorname{OCD}(\beta=.42, p<.001)$, the degree of obsession $(\beta=.42, p<.001)$ and compulsion $(\beta=.36, p<.001)$. These positive coefficients indicated that SNS addiction facilitates the severity of OCD and the corresponding obsessiveness and compulsiveness. Similarly, the Sobel test supported the significance of the suppressor effects, excluding the effects of SNS addiction and SNS intensity on the obsessive subscale.

\section{Discussion}

This research has addressed the overlap of SNS intensity and SNS addiction in predicting the measured severity of OCD and its corresponding factors of obsession and compulsion. Although it is still unclear as to whether SNS intensity is a prerequisite of SNS addiction or not (Błachnio, Przepiorka, \& Hawi, 2016; Brailovskaia et al., 2018; Orosz et al., 2016; Xie \& Karan, 2019), the positive relationship found in this research corroborates the theoretical overlap of these two aspects. Hence, this research has successfully replicated the overlap of SNS intensity and SNS addiction (Błachnio et al., 2015; Błachnio et al., 2017; Błachnio \& Przepiorka, 2016; Błachnio, Przepiorka, \& Pantic, 2016; Brailovskaia et al., 2018; Brailovskaia et al., 2019; Orosz et al., 2016; Przepiorka \& Błachnio, 2016; Turley et al., 2019). Moreover, the positive correlation suggests that these aspects are conceptually similar without redundancy. This also supports the fact that the theoretical construct of SNS addiction consists of active engagement on SNS. Hence, the prerequisite of SNS intensity is plausibly valid (Błachnio, Przepiorka, \& Hawi, 2016; Brailovskaia et al., 2018; Orosz et al., 2016; Xie \& Karan, 2019). 
The research also found that addiction towards SNS correlated significantly with the measured severity of OCD and its factors. However, the measured SNS intensity did not correlate significantly with each factor measured for OCD. These findings supported the decision to designate SNS intensity as the suppressor variable in the first predictive model (see Horst, 1941) in addition to interpreting the corresponding results as suppression instead of mediation (see MacKinnon et al., 2000). Results of the hierarchical regression further supported the significance of the measured SNS intensity as a suppressor variable, where its entry enhanced the predictive power of SNS addiction. This exemplifies the case of classical suppression (Horst, 1941). The common variance of SNS addiction and SNS intensity was removed, and thus, bolstered the predictive power of SNS addiction. Even though the existing literature has not studied the overlapping aspects of SNS intensity and SNS addiction, theoretically speaking, these two constructs share the same high levels of active SNS use (Orosz et al., 2016). By removing this common variance, the specific experiences reflected by these aspects predicted the measured severity of OCD and its factors in different manners.

After removing its common variance with SNS intensity, SNS addiction was stimulating the development of clinical symptoms such as OCD. Based on these findings, it can be deduced that SNS addiction does not link solely to depression (e.g., da Veiga et al., 2019; Foroughi et al., 2019), but also other clinical symptoms including OCD (Andreassen et al., 2016; Lee et al., 2015). The anticipated positive relationship of SNS addiction and the severity of OCD was supported by this research, suggesting that unregulated SNS use increases with the progression and severity of OCD. This result is also consistent with a past study that discovered the increased severity of OCD amongst individuals with poor control of their repetitive behaviours (Kashyap et al., 2012). Also, this corroborates Lee et al.'s (2015) findings, such that the measured addictive use of SNS predicted the severity of OCD through cognitive patterns that are exclusive to OCD. The same research revealed that the inability to regulate usage habits of SNS might be a manifestation of OCD.

In terms of the present study, it has been found that there is a positive link between SNS addiction and the measured obsession, suggesting problematic cognitions (Lee et al., 2015) and urges (Hofmann et al., 2012) as origins of SNS addiction. The results also illustrated that individuals with high levels of SNS addiction are vulnerable to compulsion. Since frequent use of SNS is needed to alleviate these urges (Hofmann et al., 2012) and stressprovoking thoughts (Lee et al., 2015), the sense of relief that one receives further reinforces the unregulated use of SNS to achieve the same euphoric experience (Grassi, 2016). Overall, it has been observed that the present findings consolidated the theoretical link between SNS addiction and OCD.

Upon removing its common variance with SNS addiction, the measured SNS intensity emerged as a negative predictor of the measured severity of OCD and its compulsion factor and did not significantly predict the obsession factor of OCD. This is consistent with the facilitative effects discovered in previous research which revealed that individuals with low self-esteem and low life satisfaction were able to elicit social benefits through intense SNS use (e.g., Ellison et al., 2007).

Similarly, other research has suggested that SNS intensity is related to meaningful usages such that SNS act as platforms to maintain connectedness with other users online (López et al., 2019). These underlying SNS usage patterns reflect on different strategies that users have employed to establish and to cultivate social benefits through this network (Ellison et al., 2011; Ellison et al., 2014). Considering its capacity to cultivate social capital, SNS intensity can be useful in mitigating the impacts of stressful situations (Błachnio et al., 2017) and clinical symptoms. Nevertheless, it should be highlighted that the protective aspect of SNS intensity was not evident previously (Labrague, 2014) due to its overlap with SNS addiction that obscured its adaptive aspects. The present research has, therefore demonstrated that the removal of this overlap unleashed the protective feature of SNS intensity. This is evident, such that it is capable of reducing the severity of OCD and compulsiveness, except for obsession. Additionally, SNS intensity did not relate meaningfully to obsessive thoughts, which was found to induce SNS addiction (Lee et al., 2015). This implies that problematic cognitive patterns (Lee et al., 2015) and urges (Hofmann et al., 2012) that underlie unregulated use of SNS are irrelevant to SNS intensity. Hence, as depicted by a recent finding on its overlap with online connection strategies (López et al., 2019), this construct denotes that highly regulated use of SNS will eventually elicit social benefits (e.g., Ellison et al., 2007). The present findings consolidated the adaptive aspects of SNS intensity by positing it as a construct that is in contrast with psychological constructs that are suggestive of impairments, such as OCD and its corresponding symptoms. 
Furthermore, the differences in the outcomes for SNS addiction and SNS intensity exemplify that these two are distinctive concepts. These findings further refute previous studies that considered SNS intensity as a prerequisite to SNS addiction (Błachnio, Przepiorka, \& Hawi, 2016; Brailovskaia et al., 2018; Orosz et al., 2016; Xie \& Karan, 2019). Instead, the research outcome suggests that these two aspects are mutually exclusive when the common variance has been diminished. This research further recommends for SNS intensity and SNS addiction to be interpreted as two separate constructs. As depicted in a previous study, while SNS can be helpful and valuable platforms that enable users to cope with stressful situations effectively, users who are socially inhibited are prone to developing SNS addiction and SNS intensity (Błachnio et al., 2017). The distinction between SNS addiction and SNS intensity is vague in the existing literature, and both have been interpreted as a similar construct. Contrastingly, the present findings suggest that only SNS intensity is protective against pathological aspects, and SNS addiction is not theoretically adaptive to all users since this construct has been linked consistently to severe OCD and its symptoms. Thus, assuming that both aspects are equivalent is erroneous since this assumption will introduce complications in the interpretation of results. This further demonstrates the significance of this research such that it has successfully highlighted the conceptual distinction between the overlapping constructs of SNS addiction and SNS intensity. Thus, this research cautions researchers against the jingle fallacy (Thorndike, 1904) in inferring the similarities between these two disparate concepts.

This research has several inherent limitations, notwithstanding its aforementioned values. Although SNS usage has been linked to several psychological outcomes, the present research findings were only limited to one clinical outcome of OCD. There is also a concern on the replicability of the demonstrated suppression since it is uncertain whether or not the demonstrated suppression applies to other psychological outcomes, such as life satisfaction that has been linked to both SNS addiction (e.g., Satici, 2019) and SNS intensity (e.g., Valenzuela et al., 2009). Therefore, this limitation marks a valuable prospect for future research on this topic. The unequal demographics of the present sample also imposed a limit to the generalisability of the research outcome. Although this study has produced significant results, the correlational design employed does not allow for causal interpretations to be made. Accordingly, the causal link between SNS use and OCD remains unresolved; it is still unclear whether SNS addiction can induce OCD, or vice-versa. The fixation on correlational design is due to the reliance on selfreported measures that are susceptible to responding bias. At the point of this investigation, there was no acceptable procedure to manipulate the usage of SNS and the severity of OCD. Upcoming research should, thus, consider employing the relevant procedures to address this limitation adequately.

In conclusion, this research has successfully disentangled the overlap between SNS intensity and SNS addiction in predicting OCD and its factors through suppression analyses. By delineating this overlap, SNS intensity and SNS addiction predicted the measured severity of OCD differently, where the former SNS intensity predicted the severity of OCD negatively, while the latter addictive tendencies toward SNS predicted it positively. This implies that SNS intensity and SNS addiction operate on a different continuum, contrasting with the extant assumption that SNS intensity is embedded in SNS addiction (Błachnio, Przepiorka, \& Hawi, 2016; Brailovskaia et al., 2018; Orosz et al., 2016; Xie \& Karan, 2019). Thus, this research cautions researchers against the jingle fallacy in interpreting the constructs of SNS intensity and SNS addiction. However, due to difficulties to replicate the results of suppression analyses (Paulhus et al., 2004; Wiggins, 1973), ensuing efforts are necessary to ensure the robustness of these results. There are positive prospects for future studies to expand on this research topic by incorporating multiple outcomes.

\section{References}

American Psychiatric Association. (2013). Diagnostic and statistical manual of mental disorders: DSM-5 ${ }^{\mathrm{TM}}$ (5th ed.). American Psychiatric Publishing, Inc.

Anderson, B., Fagan, P., Woodnutt, T., \& Chamorro-Premuzic, T. (2012). Facebook psychology: Popular questions answered by research. Psychology of Popular Media Culture, 1(1), 23-37. http://dx.doi.org/10.1037/a0026452

Andreassen, C. S., Billieux, J., Griffiths, M. D., Kuss, D. J., Demetrovics, Z., Mazzoni, E., \& Pallesen, S. (2016). The relationship between addictive use of social media and video games and symptoms of psychiatric disorders: A large-scale cross-sectional study. Psychology of Addictive Behaviors, 30(2), 252-262.

http://dx.doi.org/10.1037/adb0000160 
Andreassen, C. S., Torsheim, T., Brunborg, G. S., \& Pallesen, S. (2012). Development of a Facebook Addiction Scale. Psychological Reports, 110(2), 501-517. http://dx.doi.org/10.2466/02.09.18.PR0.110.2.501-517

Biolcati, R., Mancini, G., Pupi, V., \& Mugheddu, V. (2018). Facebook addiction: Onset predictors. Journal of Clinical Medicine, 7(6), Article 118. http://dx.doi.org/10.3390/jcm7060118

Błachnio, A., \& Przepiorka, A. (2016). Personality and positive orientation in Internet and Facebook addiction. An empirical report from Poland. Computers in Human Behavior, 59, 230-236.

http://dx.doi.org/10.1016/j.chb.2016.02.018

Błachnio, A., Przepiorka, A., \& Czuczwar, S. J. (2017). Type D personality, stress coping strategies and self-efficacy as predictors of Facebook intrusion. Psychiatry Research, 253, 33-37.

http://dx.doi.org/10.1016/j.psychres.2017.03.022

Błachnio, A., Przepiorka, A., \& Díaz-Morales, J. F. (2015). Facebook use and chronotype: Results of a crosssectional study. Chronobiology International, 32(9), 1315-1319. http://dx.doi.org/10.3109/07420528.2015.1083998

Błachnio, A., Przepiorka, A., \& Hawi, N. S. (2016). The more you use Facebook, the more you risk becoming addicted to it?: A study report. Neuropsychiatry, 6(3), 80-84. https://www.jneuropsychiatry.org/peer-review/themore-you-use-facebook-the-more-you-risk-becoming-addicted-to-it-a-study-report.html

Błachnio, A., Przepiorka, A., \& Pantic, I. (2016). Association between Facebook addiction, self-esteem and life satisfaction: A cross-sectional study. Computers in Human Behavior, 55(Part B), 701-705.

http://dx.doi.org/10.1016/j.chb.2015.10.026

Brailovskaia, J., Rohmann, E., Bierhoff, H.-W., \& Margraf, J. (2018). The brave blue world: Facebook flow and Facebook Addiction Disorder (FAD). PLoS ONE, 13(7), Article e0201484.

http://dx.doi.org/10.1371/journal.pone.0201484

Brailovskaia, J., Rohmann, E., Bierhoff, H.-W., Schillack, H., \& Margraf, J. (2019). The relationship between daily stress, social support and Facebook Addiction Disorder. Psychiatry Research, 276, 167-174.

http://dx.doi.org/10.1016/j.psychres.2019.05.014

Cheung, G. W., \& Lau, R. S. (2008). Testing mediation and suppression effects of latent variables: Bootstrapping with structural equation models. Organizational Research Methods, 11(2), 296-325.

http://dx.doi.org/10.1177/1094428107300343

Cohen, J. (1988). Statistical power analysis for the behavioral sciences (2nd ed.). Routledge.

Cohen, J. \& Cohen, P. (1975). Applied multiple correlation/regression analysis for the social sciences. Wiley.

Conger, A. J. (1974). A revised definition of suppressor variables: A guide to their identification and interpretation. Educational and Psychological Measurement, 34(1), 35-46.

https://doi.org/10.1177/001316447403400105

da Veiga, G. F., Sotero, L., Pontes, H. M., Cunha, D., Portugal, A., \& Relvas, A. P. (2019). Emerging adults and Facebook use: The validation of the Bergen Facebook Addiction Scale (BFAS). International Journal of Mental Health and Addiction, 17(2), 279-294. http://dx.doi.org/10.1007/s11469-018-0018-2

Ellison, N. B., Steinfield, C., \& Lampe, C. (2007). The benefits of Facebook "friends:" Social capital and college students' use of online social network sites. Journal of Computer-Mediated Communication, 12(4), 1143-1168. http://dx.doi.org/10.1111/j.1083-6101.2007.00367.x 
Ellison, N. B., Steinfield, C., \& Lampe, C. (2011). Connection strategies: Social capital implications of Facebookenabled communication practices. New Media \& Society, 13(6), 873-892.

http://dx.doi.org/10.1177/1461444810385389

Ellison, N. B., Vitak, J., Gray, R., \& Lampe, C. (2014). Cultivating social resources on social network sites: Facebook relationship maintenance behaviors and their role in social capital processes. Journal of Computer-Mediated Communication, 19(4), 855-870. http://dx.doi.org/10.1111/jcc4.12078

Farrar, D. E., \& Glauber, R. R. (1967). Multicollinearity in regression analysis: The problem revisited. The Review of Economics and Statistics, 49(1), 92-107. http://dx.doi.org/10.2307/1937887

Foroughi, B., Iranmanesh, M., Nikbin, D., \& Hyun, S. S. (2019). Are depression and social anxiety the missing link between Facebook addiction and life satisfaction? The interactive effect of needs and self-regulation. Telematics and Informatics, 43, Article 101247. http://dx.doi.org/10.1016/j.tele.2019.101247

Fowler, J., Gullo, M. J., \& Elphinston, R. A. (2020). Impulsivity traits and Facebook addiction in young people and the potential mediating role of coping styles. Personality and Individual Differences, 161, Article 109965. https://doi.org/10.1016/j.paid.2020.109965

Frost, R. L., \& Rickwood, D. J. (2017). A systematic review of the mental health outcomes associated with Facebook use. Computers in Human Behavior, 76, 576-600. http://dx.doi.org/10.1016/j.chb.2017.08.001

Gaylord-Harden, N. K., Cunningham, J. A., Holmbeck, G. N., \& Grant, K. E. (2010). Suppressor effects in coping research with African American adolescents from low-income communities. Journal of Consulting and Clinical Psychology, 78(6), 843-855. http://dx.doi.org/10.1037/a0020063

Gibbs, N. A. (1996). Nonclinical populations in research on obsessive-compulsive disorder: A critical review. Clinical Psychology Review, 16(8), 729-773. https://doi.org/10.1016/S0272-7358(96)00043-8

Goodman, W. K., Price, L. H., Rasmussen, S. A., Mazure, C., Delgado, P., Heninger, G. R., \& Charney, D. S. (1989). The Yale-Brown Obsessive Compulsive Scale: II. Validity. Archives of General Psychiatry, 46(11), 1012-1016. http://dx.doi.org/10.1001/archpsyc.1989.01810110054008

Goodman, W. K., Price, L. H., Rasmussen, S. A., Mazure, C., Fleischmann, R. L., Hill, C. L., Heninger, G. R., \& Charney, D. S. (1989). The Yale-Brown Obsessive Compulsive Scale: I. Development, use, and reliability. Archives of General Psychiatry, 46(11), 1006-1011. http://dx.doi.org/10.1001/archpsyc.1989.01810110048007

Grassi, G. (2016). Obsessive-compulsive disorder clinical staging: From endophenotype to behavioral addiction (a theoretical framework). European Neuropsychopharmacology, 26(5), 897-897.

http://dx.doi.org/10.1016/j.euroneuro.2015.06.031

Hofmann, W., Vohs, K. D., \& Baumeister, R. F. (2012). What people desire, feel conflicted about, and try to resist in everyday life. Psychological Science, 23(6), 582-588. http://dx.doi.org/10.1177/0956797612437426

Horst, P. (1941). The role of the predictor variables which are independent of the criterion. Social Science Research Council, 48, 431-436.

Hussain, Z., \& Griffiths, M. D. (2018). Problematic social networking site use and comorbid psychiatric disorders: A systematic review of recent large-scale studies. Frontiers in Psychiatry, 9, Article 686.

http://dx.doi.org/10.3389/fpsyt.2018.00686

Jelenchick, L. A., Eickhoff, J. C., \& Moreno, M. A. (2013). "Facebook depression?" Social networking site use and depression in older adolescents. Journal of Adolescent Health, 52(1), 128-130.

http://dx.doi.org/10.1016/j.jadohealth.2012.05.008 
Junco, R. (2013). Comparing actual and self-reported measures of Facebook use. Computers in Human Behavior, 29(3), 626-631. http://dx.doi.org/10.1016/j.chb.2012.11.007

Kashyap, H., Fontenelle, L. F., Miguel, E. C., Ferrão, Y. A., Torres, A. R., Shavitt, R. G., Ferreira-Garcia, R., do Rosário, M. C., \& Yücel, M. (2012). 'Impulsive compulsivity' in obsessive-compulsive disorder: A phenotypic marker of patients with poor clinical outcome. Journal of Psychiatric Research, 46(9), 1146-1152.

http://dx.doi.org/10.1016/j.jpsychires.2012.04.022

Kelley, T. L. (1927). Interpretation of educational measurements. World Book.

Kim, C., \& Shen, C. (2020). Connecting activities on social network sites and life satisfaction: A comparison of older and younger users. Computers in Human Behavior, 105, Article 106222.

https://doi.org/10.1016/j.chb.2019.106222

Kline, R. B. (2005). Principles and practice of structural equation modeling (2nd ed.). Guilford Press.

Kuss, D. J., \& Griffiths, M. D. (2017). Social networking sites and addiction: Ten lessons learned. International Journal of Environmental Research and Public Health, 14(3), Article 311. http://dx.doi.org/10.3390/ijerph14030311

Labrague, L. J. (2014). Facebook use and adolescents' emotional states of depression, anxiety, and stress. Health Science Journal, 8(1), 80-89.

Lee, S.-L., Kim, J.-A., Golden, K. J., Kim, J.-H., \& Park, M. S.-A. (2016). A cross-cultural examination of SNS usage intensity and managing interpersonal relationships online: The role of culture and the autonomous-related selfconstrual. Frontiers in Psychology, 7, Article 376. http://dx.doi.org/10.3389/fpsyg.2016.00376

Lee, S.-L., Park, M. S.-A., \& Tam, C.-L. (2015). The relationship between Facebook attachment and obsessivecompulsive disorder severity. Cyberpsychology: Journal of Psychosocial Research on Cyberspace, 9(2). Article 6. http://dx.doi.org/10.5817/CP2015-2-6

López, S. Z., Martínez, M., \& Pastor, M. A. (2019). Development and validation of a questionnaire in Spanish for evaluating Facebook use. Current Psychology. Advance online publication. http://dx.doi.org/10.1007/s12144-01900171-7

Marsh, H. W. (1994). Sport motivation orientations: Beware of jingle-jangle fallacies. Journal of Sport and Exercise Psychology, 16(4), 365-380. http://dx.doi.org/10.1123/jsep.16.4.365

McCord, B., Rodebaugh, T. L., \& Levinson, C. A. (2014). Facebook: Social uses and anxiety. Computers in Human Behavior, 34, 23-27. http://dx.doi.org/10.1016/j.chb.2014.01.020

MacKinnon, D. P., Krull, J. L., \& Lockwood, C. M. (2000). Equivalence of the mediation, confounding and suppression effect. Prevention Science, 1(4), 173-181. https://doi.org/10.1023/A:1026595011371

O'Keeffe, G. S., Clarke-Pearson, K., \& Council on Communications and Media. (2011). The impact of social media on children, adolescents, and families. Pediatrics, 127(4), 800-804. http://dx.doi.org/10.1542/peds.2011-0054

Orosz, G., Tóth-Király, I., \& Bőthe, B. (2016). Four facets of Facebook intensity — The development of the Multidimensional Facebook Intensity Scale. Personality and Individual Differences, 100, 95-104.

http://dx.doi.org/10.1016/j.paid.2015.11.038

Pantic, I., Damjanovic, A., Todorovic, J., Topalovic, D., Bojovic-Jovic, D., Ristic, S., \& Pantic, S. (2012). Association between online social networking and depression in high school students: Behavioral physiology viewpoint. Psychiatria Danubina, 24(1), 90-93. 
Paulhus, D. L., Robins, R. W., Trzesniewski, K. H., \& Tracy, J. L. (2004). Two replicable suppressor situations in personality research. Multivariate Behavioral Research, 39(2), 303-328.

http://dx.doi.org/10.1207/s15327906mbr3902_7

Przepiorka, A., \& Błachnio, A. (2016). Time perspective in Internet and Facebook addiction. Computers in Human Behavior, 60, 13-18. http://dx.doi.org/10.1016/j.chb.2016.02.045

Rachman, S., \& de Silva, P. (1978). Abnormal and normal obsessions. Behaviour Research and Therapy, 16(4), 233248. https://doi.org/10.1016/0005-7967(78)90022-0

Rosen, L. D., Whaling, K., Carrier, L. M., Cheever, N. A., \& Rokkum, J. (2013). The Media and Technology Usage and Attitudes Scale: An empirical investigation. Computers in Human Behavior, 29(6), 2501-2511.

http://dx.doi.org/10.1016/j.chb.2013.06.006

Satici, S. A. (2019). Facebook addiction and subjective well-being: A study of the mediating role of shyness and loneliness. International Journal of Mental Health and Addiction, 17(1), 41-55. http://dx.doi.org/10.1007/s11469017-9862-8

Satici, S. A., \& Uysal, R. (2015). Well-being and problematic Facebook use. Computers in Human Behavior, 49, 185190. http://dx.doi.org/10.1016/j.chb.2015.03.005

Scott, G. G. (2014). More than friends: Popularity on Facebook and its role in impression formation. Journal of Computer-Mediated Communication, 19(3), 358-372. http://dx.doi.org/10.1111/jcc4.12067

Selfhout, M. H. W., Branje, S. J. T., Delsing, M., ter Bogt, T. F. M., \& Meeus, W. H. J. (2009). Different types of Internet use, depression, and social anxiety: The role of perceived friendship quality. Journal of Adolescence, 32(4), 819-833. http://dx.doi.org/10.1016/j.adolescence.2008.10.011

Seol, S.-H., Kwon, J. S., \& Shin, M.-S. (2013). Korean self-report version of the Yale-Brown Obsessive-Compulsive Scale: Factor structure, reliability, and validity. Psychiatry Investigation, 10(1), 17-25.

https://doi.org/10.4306/pi.2013.10.1.17

Sheldon, P. (2008). The relationship between unwillingness-to-communicate and students' Facebook use. Journal of Media Psychology, 20(2), 67-75. http://dx.doi.org/10.1027/1864-1105.20.2.67

Sigerson, L., \& Cheng, C. (2018). Scales for measuring user engagement with social network sites: A systematic review of psychometric properties. Computers in Human Behavior, 83, 87-105.

http://dx.doi.org/10.1016/j.chb.2018.01.023

Steinfield, C., Ellison, N. B., \& Lampe, C. (2008). Social capital, self-esteem, and use of online social network sites: A longitudinal analysis. Journal of Applied Developmental Psychology, 29(6), 434-445.

http://dx.doi.org/10.1016/j.appdev.2008.07.002

Steketee, G., Frost, R., \& Bogart, K. (1996). The Yale-Brown Obsessive Compulsive Scale: Interview versus selfreport. Behaviour Research and Therapy, 34(8), 675-684. http://dx.doi.org/10.1016/0005-7967(96)00036-8

Tabachnick, B. G., \& Fidell, L. S. (2012). Using multivariate statistics (6th ed.). Pearson Education.

Thorndike, E. L. (1904). An introduction to the theory of mental and social measurements. Teachers College, Columbia University.

Turley, J., Lewis, C. A., Musharraf, S., Malik, J. A., \& Breslin, M. J. (2019). Psychometric properties of three measures of "Facebook engagement and/or addiction" among a sample of English-speaking Pakistani university students. International Journal of Mental Health and Addiction, 17(4), 995-1007. http://dx.doi.org/10.1007/s11469018-9963-Z 
Uysal, R., Satici, S. A., \& Akin, A. (2013). Mediating effect of Facebook® addiction on the relationship between subjective vitality and subjective happiness. Psychological Reports, 113(3), 948-953.

http://dx.doi.org/10.2466/02.09.18.PR0.113×32z3

Valenzuela, S., Park, N., \& Kee, K. F. (2009). Is there social capital in a social network site?: Facebook use and college students' life satisfaction, trust, and participation. Journal of Computer-Mediated Communication, 14(4), 875-901. http://dx.doi.org/10.1111/j.1083-6101.2009.01474.x

Watson, D., Clark, L. A., Chmielewski, M., \& Kotov, R. (2013). The value of suppressor effects in explicating the construct validity of symptom measures. Psychological Assessment, 25(3), 929-941.

http://dx.doi.org/10.1037/a0032781

Wiggins, J. S. (1973). Personality and prediction: Principles of personality assessment. Addison-Wesley Publishing Co.

Wilson, K., Fornasier, S., \& White, K. M. (2010). Psychological predictors of young adults' use of social networking sites. Cyberpsychology, Behavior, and Social Networking, 13(2), 173-177. http://dx.doi.org/10.1089/cyber.2009.0094

Xie, W., \& Karan, K. (2019). Predicting Facebook addiction and state anxiety without Facebook by gender, trait anxiety, Facebook intensity, and different Facebook activities. Journal of Behavioral Addictions, 8(1), 79-87.

http://dx.doi.org/10.1556/2006.8.2019.09

\section{Correspondence to:}

Soon Li Lee

Faculty: Department of Psychology

Jalan Lagoon Selatan, Bandar Sunway, 47500 Subang Jaya, Selangor

Malaysia

Email: Soonli_Lee89(at)outlook.com/soonli.lee(at)monash.edu

Editorial record: First submission received on March 15, 2020. Revisions received on July 15, 2020, December 1, 2020, January 28, 2021 and March 30, 2021. Accepted for publication on April 1, 2021.

Editor in charge: Michel Walrave

\section{About Author}

Dr. Soon Li Lee is a cyberpsychologist who specializes in technological addiction (e.g. Facebook addiction, smartphone addiction). He focuses on the detrimental effects of technological addiction, mainly on users' psychological well-being. Dr. Lee is currently working on distinguishing the theoretical constructs of normal (e.g. regular Facebook use) and maladaptive (e.g. Facebook addiction) social network sites usages. He is also interested in individual differences (e.g. human personality, cultural orientations). 